\title{
Safe at Home \\ Co-curricular Spaces for Generative, (un)safe Conversations
}

Chris Rosser

Oklahoma Christian University

\begin{abstract}
Third space describes an intentional space where normative assumptions are challenged by shared encounter with cultural and ideological otherness; third spaces open possibilities for transformational education. Beam Library at Oklahoma Christian University generates third space experiences through co-curricular events that engage the intersection of faith and culture. Specifically, our Safe at Home chapel exists as a generous (un)safe space that facilitates crucial conversation about gender, sexuality, and faith, empowering students who may feel unsafe because they are or affirm LGBTQIA individuals. Library initiatives like Safe at Home chapel create third space learning experiences, positioning the library at the intersection of formation and information, re-visioning the library as facilitator of generative conversation in a generously hospitable space. As co-curricular entities, academic libraries are aptly situated for the creation of third spaces, demonstrating the educational and formational value of the library as third space.
\end{abstract}

\section{AT THE INTERSECTION OF FORMATION AND INFORMATION}

Greeting. Good afternoon, my name is Chris Rosser, and I serve as Theological Librarian at Oklahoma Christian University, a small, private, liberal arts institution associated with the Stone-Campbell Movement, for any who are familiar with that particular branch of American Protestantism's forking tree. Since Oklahoma Christian's Beam Library is small, I also oversee our instruction and educational initiatives. Before we begin, let me say: I've been able to attend the Atla Annual conference for several years, but had to miss last year and definitely noticed the difference. For me, Atla is a place for 
sharing and sharpening ideas; I always return with new insights to pass on to colleagues that make our work as librarians and our thinking about our work as librarians better, clearer. I am grateful to Atla for these experiences, and I appreciate your presence and participation today as we discuss Safe at Home: Co-curricular spaces for generative, (un)safe conversations.

This afternoon, I'd like to share how Beam Library is creating third space learning experiences, ideas and initiatives that more clearly position the library at an intersection of information and formation and that re-vision the library as facilitator on our campus of generative conversations in generously hospitable spaces.

Specifically, I'd like to share with you about our Safe at Home chapel, which exists as a generous (un)safe space that facilitates crucial conversation about gender, sexuality, and faith, engaging with students who may feel unsafe because they are or affirm LGBT+ individuals. Beyond sharing about Safe at Home, here is the crux of what I hope to communicate: as co-curricular entities, academic libraries are aptly situated for the creation of third spaces, which in our context we envision as an intentional space where perceived normative rules and structures are challenged by shared encounters with cultural and ideological otherness. To better contextualize Safe at Home on our campus, let me first describe the Beam Library, who we are and how we serve within the Oklahoma Christian University community.

Oklahoma Christian University is currently undergoing rebranding-a new, contemporary logo and updated language to better express who we are as a University, in particular the importance of the life story of each individual student. In the library, we've also been hammering on language to capture and communicate who we are, what we do, and even more specifically how and why we serve. Currently, we're using the construct (in)formation to help communicate how we envision Beam Library existing on our campus at the intersection of formation and information. We are re-visioning the library as (in)formational third space. You can see here some of the language we're using to help clarify our understanding of what Beam Library is and what we do.

Information is readily associated with an academic library; formation of students is perhaps our aspiration, especially as many of us work within institutions that make faith formation central to 
mission, and it's likely that all of us desire to form as well as inform the students we encounter and the campus communities we serve. But the library has a problem: we are a co-curricular space, positioned outside the classroom, and it is difficult to meaningfully assess how we form and inform students in direct relation to student learning outcomes and to University learning outcomes.

We've come to recognize that revisioning the academic library as (in)formational third space opens possibilities for transformational education and measurable demonstration of the library's manifold value. Before unpacking what we mean by "the library as (in)formational third space," let me explain some of the philosophy of teaching that informs our thinking.

We talk a lot about faith and learning on our campuses. It just so happens that ideally the center of learning is also the center of love: love and learning each require encounter with that which is not self, something different, someone who is other. Lives transformed for Christian faith, scholarship, and service-in other words, lives transformed by learning and by love-such lives are necessarily shaped by and through encounter with difference. Loving neighbor (difference) as self (sameness) is central to Christian faith; similarly, souls enlarge by and through encounter with new knowledge (difference). Such encounter is central to learning, and the Beam Library intentionally facilitates encounter for the sake of learning, as an expression of love.

Beam Library exists as a generously hospitable space for encounter at the center of OC's campus, and the library itself is central to our campus. Our purpose as librarians and as educators is to reach and transform each student's heart; we recognize that the truest path to the heart is not through the head but through the gut. Therefore, we strive to bring learning to spaces of desire. Transforming the heart involves reorienting or clarifying desire so that students' love (i.e., desire) vectors more truly toward God and neighbor. Love is both the motivation and the goal of our work and teaching. In other words, formation is essential to the information we provide.

For several years now, we've understood the library to be third space, which as I mentioned is an intentional space where perceived norms and structures are challenged by shared encounters with cultural and ideological otherness. Beam Library is also a co-curricular space, positioned outside the classroom yet integral 
to classroom learning and student success. As a co-curricular third space, our distinctiveness is most clearly demonstrated by our ability to recognize, understand, and capitalize on co-curricular identity. We are a third space for co-curricular learning; we are a third space for co-curricular formation; we are a third space for co-curricular encounter.

Meaningful encounter with otherness is the primary context and catalyst for transformative educational experiences. And the kind of encounter we're talking about is the context in which formative education and spiritual formation happen-encounter with otherness is the heart of faith and learning. Librarians and staff understand ourselves as facilitating transformational encounters that foster academic growth and spiritual formation.

Education electrified by formative experience-that is the cumulation of our work, the faithful learner's posture we intentionally nurture in our students and within the OC community. As a library entity, we recognize who we are and have a vision for who we might become. We understand ourselves to be a hub of learning and formative experiences within our campus. We are positioned at an intersection of information and formation; we recognize the library as facilitating generative, complex conversations in generously hospitable spaces.

\section{LIBRARY AS CO-CURRICULAR THIRD SPACE}

So that's some of the thinking that supports and informs how we envision the library as third space. While there are many ways of thinking about third space, in our context third space refers to liminal learning spaces created where dominant culture, with its normative rules and assumptions, intersects with difference or otherness. Third space is the space between: for individuals, it's the space between I and Thou; in classrooms, it's the intersection of students' out-of-school experiences, knowledge, and culture and the curricular content, rules, and school culture; in society, third space is the borderland where cultural minority groups navigate dominant cultural norms.

In a very real sense, the academic library-though considered by many (especially librarians) to be the hub or beating heart of student 
learning and education-is already positioned on the fringes of the classroom, the liminality of in-class and out-of-class experiences, the borderland between classroom and cafeteria.

Following trends in student learning, many libraries have shifted toward offering intentional space for collaboration-study areas are redesigned, "maker spaces" developed, and the library is re-tooled as a "learning commons." The evolving library landscape presents a challenge to librarians as we roll up cardigan sleeves, sheath our shushing-fingers, and re-imagine what academic libraries are and what we're becoming.

First, what we are. The library's reality as a co-curricular institution presents a challenge for articulating and assessing our value in terms of learning outcome achievement. Academic student learning outcomes associated with the library and/or information literacy are generally connected to class research assignments, while library instruction is most often co-curricular. So for librarians, it can be difficult to show our value in terms of direct fulfilment of learning outcomes.

Now, what we're becoming. Envisioning the library as third space reflects an emerging trend in librarianship ripe with potential for capturing the significance of the library for transformative, co-curricular learning. Third spaces open possibilities for transformational learning by broadening worldview, encouraging selfreflection, and enlarging the soul through formational learning experiences. We believe that encounter with difference is both the spark and the medium of transformative education.

As a co-curricular third space, Beam Library is positioned to facilitate encounters that simultaneously challenge and shape identity. We believe that encounters with difference open spaces pregnant with potential for learning, and we believe that learning experiences in third spaces should be measured and outcomes articulated, assessed, and mapped to University learning outcomes.

Assessment has become a top priority for many institutions of higher education, especially as we seek to maintain accreditation. And academic libraries, which as we know have always been central to the academic enterprise-providing, facilitating, and instructing in the use of resources-must also assess their place and value within our academic institutions. 
Probably many of you are familiar with the Association of College and Research Libraries study, Academic Library Impact on Student Learning and Success (ACRL, 2017), which highlights the value of the academic library in terms of its general contribution to learning. The report spells good news for academic libraries, outlining empirically verifiable ways that the library benefits, enhances, strengthens, boosts, and increases student learning and success. Note, however, that each of these positive terms-benefits, enhances, strengthens, boosts, and increases-positions the library in an auxiliary relation to the core. The glaring problem for assessment in terms of the centrality of the academic library in fulfilling student learning outcomes remains: the library is a co-curricular institution, and information literacy instruction or research interactions are often peripheral to the courses in which projects are assigned, and therefore instruction is difficult to assess in terms of direct support and fulfilment of student learning outcomes.

In other words, because student learning outcomes are connected to class research projects, while library instruction-whether in class or individual, virtual or face-to-face-is co-curricular, librarians face a challenge in directly assessing and mapping our instruction to student learning outcomes and, consequently, to program or university learning outcomes. The problem, bare-bones: for instruction librarians, it can be difficult to show our value in terms of direct fulfilment of learning outcomes, to meaningfully show how we both form and inform students.

\section{CHAPEL AS NORMALIZED “THIRD SPACE”}

So, we're thinking about how to assess our capacity to both form and inform students. Briefly, I'd like to introduce you to two third space weekly chapel events the library facilitates as illustrative of the formational power and potential of third space creation.

In our context, we are able to capitalize on a normalized type of space-weekly chapel meetings-and enfuse chapel with third space learning experiences. Students at Oklahoma Christian University are required to attend a certain number of approved, spirituallyoriented events, including chapel events. For several years, the library has facilitated Beam Chapel and Safe at Home Chapel. These 
chapels offer librarians and library staff an important means for demonstrating our connectedness to the spiritual life and formation of our campus community.

Let me briefly overview Beam Chapel, which introduced us to the vibrant potential of third space learning. For thirteen semesters, Beam Chapel has intentionally offered a dynamic space for engaging gritty questions that impact faith and the culture(s) we inhabit, questions arising from the dark of film, literature, and television. We envision Beam Chapel as a third space: in relation to our larger campus community, Beam Chapel hollows out a space for acknowledging, questioning, celebrating, and critiquing assumptions about faith, popular culture, and inherited traditions from a multiplicity of backgrounds and beliefs. Through chapel, librarians foster meaningful conversations and contribute to the University's spiritual mission of transforming lives for Christian faith and service. In fact, Beam Chapel recently received a very positive write-up in the Oklahoma Humanities newsletter. Semester themes are secondcommandment driven: Beam Chapel exists at intersections of faith and popular culture as a reflective and questioning space where participants discern together how to enact the commandment to "Love the neighbor as the self." This orientation characterizes Safe at Home chapel as well.

Since Fall 2015 Safe at Home chapel has existed to provide a safe space for thoughtful and respectful conversations about gender, sexuality, and church. Facilitators of the chapel hope to encourage dialogue, foster positive relationships and understanding, and increase experiences of feeling "safe at home" for all students. So, Safe at Home exists as a generous, liminal, (un)safe space that fosters connection and facilitates crucial conversation about faith, gender, and sexuality.

By using the construct (un)safe, we acknowledge the reality that this chapel is not entirely "safe" despite best intentions. Certainly, characterizing the chapel as a "safe space" does not imply coddling students by telling them what we think they want to hear or protecting them from difference or dissent. On the contrary, Safe at Home offers an important space for acknowledging students who may feel unsafe because they are or affirm LGBTQ+ individuals. Safe at Home challenges participants toward hospitality and love; in fact, our mantra is 
Romans 13:10, which reminds us that "love does no harm to neighbor; therefore, love is keeping the law."

Currently, thirteen coordinators from departments across campus help to advise, plan, and direct the chapel. Three librarians serve as coordinators of the chapel with other faculty and staff who represent a diversity of perspectives on questions of gender, sexuality, and Christian faith. Coordinators recognize the enormous complexity of such questions; society, biology, and the Bible resist easy answers. Our shared goal is to provide a theologically-informed ethic by which students learn to navigate complexity, guided primarily by an orientation toward love for neighbor. Coordinators believe that this chapel and the chapel coordinators themselves are valuable and necessary for Oklahoma Christian: valuable because they mentor and show compassion to students for whom compassion desperately matters and necessary because the chapel serves as a "pressure valve." Questions of sexuality, gender, and church have not become highly politicized or volatile on our campus, and we believe the existence of Safe at Home and the gentle, behind-the-scenes work of coordinators (and others as well) increases students' experience of OC as home and provides an avenue for loving and respectful discourse.

The term safe space refers to people as well as places. We envision three primary functions for coordinators:

Information: We help establish OC as an informed community.

Communication: We facilitate dialogue with administration and others.

Advocacy: We protect privacy, preserve dignity, and position ourselves alongside the vulnerable (i.e., those who feel unsafe at home).

For students who are questioning, Safe at Home is a source of both information and formation. Some are questioning personal identity; others are questioning beliefs; many are questioning responses by church and family to LGBT+ individuals; many are likewise questioning what it means to "love the neighbor as the self." Safe at Home as third space intentionally fosters orientation toward love for neighbor so that both students and non-student participants have reported deepened willingness to love and engage those whose thinking is radically different and even perceived as adversarial. As one participant 
noted, "It has really helped me to try and be more empathetic with people who are not affirming."

Among other implications, "safe at home" implies protection, inclusion, and embrace.

Protection: a campus culture is intentionally fostered that promotes understanding.

Inclusion: spaces for formation and channels for communication are developed so that LGBT+ students are afforded voice and place among this community.

Embrace: a generously hospitable campus culture is intentionally fostered so that LGBT+ students experience welcome in the name of Jesus.

We believe that love obligates us to deeply care for all others regardless of personal perspective or conviction. By working to foster a generously hospitable campus culture, Safe at Home exists to better fulfill the vision that OC is home for LGBT+ individuals in our community.

\section{ASSESSING LOVE AND LEARNING IN CO-CURRICULAR SPACES}

Because of its longevity, we've articulated, mapped, and been measuring outcomes for Beam Chapel, primarily via an electronic survey. Results are encouraging and demonstrate the significance of Beam Chapel in terms of student formation.

Oklahoma Christian University has established a constellation of seven University Core Outcomes. In order to better assess how Beam Chapel helps to fulfil student learning outcomes related to University learning outcomes (ULO), librarians developed and deploy a yearly survey that maps responses to articulated outcomes. Through Beam Chapel:

- Students will recognize that faith, discipleship, and Christian spirituality are not compartmentalized but richly inform all aspects of life, including our experience of literature, art and culture. (Maps to the ULO Active Faith.)

- Students will explore Christian faith within the milieu of popular culture. (Maps to the ULO Foundational Knowledge.)

- Students will participate in a community of information and 
resource sharing. (Maps to the ULO Information Literacy.)

- Students will be more critically reflective in the ways they think about and engage elements of popular culture (e.g., film, music, TV, art, etc.). (Maps to the ULO Creative and Critical Thinking.)

- Students will share ideas through discussion and student-led presentations. (Maps to the ULO Effective Communication.)

- Students will gain a better appreciation for otherness and for the implications of love thy neighbor as thyself. (Maps to the ULO Personal, Social, and Global Stewardship.)

Chapel facilitators foster meaningful conversations among participants and demonstrate the library's capacity as a significant space for transformative learning, as evidenced by participant survey responses, some of which are displayed on the slide. Also, from Fall 2017 to Spring 2019, fifteen students led presentations; two students presented with us at a national conference where we talked about the library as third space, and their presentations became part of their Honors capstone projects.

Concerning Safe at Home, over the years we have requested qualitative feedback from students (and non-student participants), but this semester we developed an anonymous survey instrument which we'll likely use for several years; responses map to the University Learning Outcome for Personal, Social, and Global Stewardship (primarily because this outcome recognizes the importance of fostering awareness of and appreciation for diverse thinking and identities). Twenty student-participants responded to this semester's survey; we're OK with that number since it reflects about $40 \%$ of weekly attendance this semester. You can see the simple instrument we developed on the slide.

To the prompt "Chapel has increased my awareness of LGBTQ+ identity on campus," 95\% indicated that experiences in chapel have been formative in this way. Eighty percent indicated that experiences in chapel have "increased my sensitivity to LGBTQ+ identity on campus"; 80\% indicated that experiences have "increased my understanding of LGBTQ+ stories"; and 80\% indicated that experiences in chapel have "deepened my compassion for members of the LGBTQ+ community." To the prompt "Chapel has increased my awareness of 
allies on campus," $90 \%$ indicated that experiences in chapel have been formative in this way.

Safe at Home chapel has now weathered early storms that threatened its sustainability, and we are beginning to hammer out outcomes that capture and communicate formation through this third space experience. I'd like to share a few examples of student feedback that connect well with the transformative third space experiences we're hoping to generate.

One student comments that chapel experiences have helped in "understanding my neighbor. Understanding helps my love for them grow." Another student reports, "I never really had too much knowledge on this subject, despite being part of the LGBTQ community. This chapel is really good for learning more of people's personal knowledge and opinions of this, and that's very valuable." And another student comments, "As Christians we're kinda expected to keep anything that doesn't fit the mold on the down low, so being gay or transgender is frowned upon. By talking about it and getting rid of the mystery about being gay or transgender really helps me love others, any way they come!"

Since the chapel averages between ten and fifteen faculty, staff, and guests weekly, we also surveyed non-student participants. One respondent notes that the chapel:

has given me language to encourage others to support those who are minorities. It is critical that Safe at Home continue to provide vocabulary to talk in "current language" about those who are on the LGBTQIA spectrum. Language helps individuals on the outside know that others different from themselves exist.

Another non-student respondent noted, “Throughout my time in Safe at Home I believe the stories and experiences that people have shared have been the most moving and helpful. When you can put yourself in someone else's shoes it always helps put things in a new perspective."

Negative feedback from both student and non-student respondents primarily focused on the one-sidedness of Safe at Home conversations. For example, a student commented, "Chapel 
has served as an echo chamber for the exact same idea each week." This student went on to describe their desire for a more debate-style experience, two views pitted against each other, iron sharpening iron with clanks and sparks and heat. We have intentionally resisted debate. Safe at Home is a co-curricular third space that is also a chapel space; it is thus a sacred space for holy encounter, a space for learning to love both difference and sameness, a space inhabited by many who are our campus community's most vulnerable members. For students on our campuses who experience challenges from mental health and mental stress, third space can become a space of welcome, respite, and hope. As one student commented, "Safe at home has offered this interesting idea of respite, a sanctuary away from 'home' in which the hard questions can be truly dug into with a passion and drive to actually understand, to better ourselves and therefore the lives of our neighbours."

In our context, Beam Library facilitates encounter with difference by engaging the intersections of faith, gender, sexuality, and popular culture, fostering conversations that are often perceived as taboo on a campus like ours. Re-visioning the library as third space helps us realize the potential of co-curricular third spaces on our campus.

Through third space initiatives, we hope to better position the library at the intersection of formation and information. Generative conversation in a generously hospitable space characterizes both Beam and Safe at Home chapels. We're developing ways to meaningfully assess both if and how students are formed by the third space experiences intentionally provided by the library.

So now, we'll open up for questions and discussion, but in conclusion here's a recap: on our campus, the library is positioned at an intersection of information and formation; we recognize the library as facilitating generative, complex conversations in generously hospitable spaces. Beam Library is striving to be an (in)formational third space. I've appreciated this opportunity to share with you how the library-itself a co-curricular space-can intentionally create third space experiences and how we can meaningfully measure those experiences to better demonstrate the manifold value of the library. So I'd love to continue this conversation and hear about your own initiatives like Safe at Home chapel that create third space learning experiences. Thank you for listening today. 